This item was submitted to Loughborough's Institutional Repository by the author and is made available under the following Creative Commons Licence conditions.

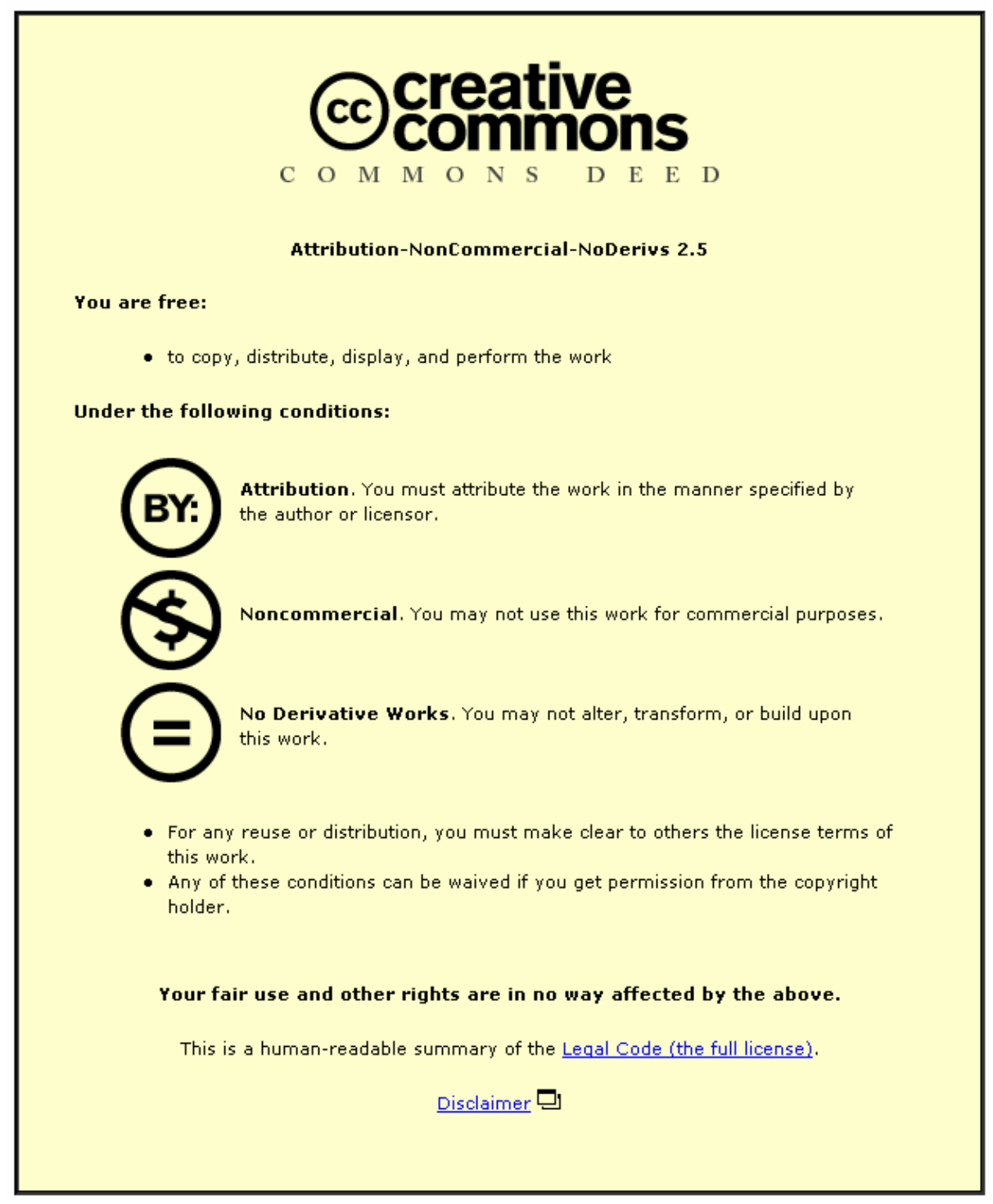

For the full text of this licence, please go to: http://creativecommons.org/licenses/by-nc-nd/2.5/ 


\title{
Cyclic Triaxial Tests on Clay Subgrades for Analytical Pavement Design
}

\author{
Matthew. W. Frost, ${ }^{1}$ \\ Paul. R. Fleming, ${ }^{2}$ \\ Christopher. D. F. Rogers. ${ }^{3}$
}

\section{ABSTRACT}

To introduce a performance specification, pavement foundations must be designed using analytical methods incorporating the laboratory measured parameters of resilient elastic modulus and resistance to permanent deformation of the subgrade and foundation materials. This paper presents results from a program of repeated load triaxial tests performed on a range of fine-grained subgrades prepared in a number of states to evaluate these parameters for various design conditions. The results highlight several difficulties in measuring small strains on 'undisturbed' soils over a large strain range and in predicting and modeling long-term behavior. However testing at higher strains has shown that the deviator stress at which the cumulative permanent deformation starts to increase significantly, termed the 'threshold stress', approximates to $50 \%$ of the deviator stress at failure. In addition, the resilient modulus of the soils is shown to approach a low asymptotic value at higher deviator stress. Comparison between elastic and plastic behavior shows that the deviator stress at 'threshold' coincides with the stiffness asymptote. Using these correlations a simplified mechanistic design method for pavement foundations is proposed.

\section{KEY WORDS}

resilient stiffness, repeated load, triaxial testing, pavement design, permanent deformation

1. Senior Lecturer in Geotechnical Engineering. The School of Property and Construction, The Nottingham Trent University, Burton Street, Nottingham, UK. Matthew.Frost@NTU.ac.uk.

2. Lecturer in Geotechnical Engineering, Department of Civil and Building Engineering, Loughborough University, Loughborough, UK. P.R.Fleming@lboro.ac.uk.

3. Professor of Geotechnical Engineering, Department of Civil Engineering, University of Birmingham, Edgbaston, Birmingham, UK. C.D.F.Rogers@bham.ac.uk. 


\section{INTRODUCTION TO UK PAVEMENT FOUNDATION DESIGN AND RESEARCH STUDY}

UK road pavements are traditionally designed in two stages, using one or more empirically designed road foundation layers (normally constructed of granular or stabilized materials) to provide a foundation upon which to construct the structural pavement layers. The road foundation consists of capping (where necessary) and sub-base overlying the natural soil subgrade or embankment fill. The capping layer is a subgrade improvement layer to facilitate good compaction of the overlying layers. Capping is traditionally an inexpensive granular material that is ideally obtained locally, a recycled material (e.g. asphalt planings) or stabilized subgrade soil. Sub-base is normally an imported, well-graded, high quality, granular material. It acts as a regulating course upon which to compact the bound layers as well as contributing directly to the structural performance of the pavement.

The design included in the current UK specification for road foundations (MCHW, 1994) uses a recipe approach, whereby selected materials are laid and compacted with specified plant in a specified manner to achieve a minimum assumed level of performance. The pavement foundation designs primarily use the California Bearing Ratio (CBR) to characterize the subgrade, capping and sub-base materials. The CBR is used as a measure of both material strength and stiffness. Although the use of CBR as a performance parameter is widely acknowledged as being not wholly satisfactory (Brown, 1996), CBR has arguably provided a trusted empirical indicator of adequate material behavior. Such an empirical approach is unlikely, however, to result in the efficient use of materials and plant, does not easily allow for the use of recycled, new or marginal materials, and does not permit the use of rigorous analytical design procedures.

To overcome the problems of such an empirical approach the UK Highways Agency funded research to develop a performance specification for pavement foundation design and construction which would incorporate laboratory and field measurements of stiffness and resistance to permanent deformation. This paper presents findings from repeated load triaxial testing of fine-grained subgrades typical of those found in the UK, which formed part of the laboratory study for the research program. The aim of this testing was to gain an understanding of the performance properties of clay subgrades and attempt to link these into a specification 
that incorporated analytical design and field compliance testing. The wider study included three purpose-built field trials that were used to test a variety of dynamic plate bearing tests (for resilient modulus) and penetration tests (for shear strength), similar tests on live sites, smaller-scale laboratory tests of such equipment, and characterisation tests of clays and granular materials.

This paper describes the requirements of a performance specification for pavement foundations and the basic principles of pavement loading, material states and material behavior that need to be considered to achieve a fully analytical pavement foundation design. Data are presented from an extensive series of repeated load triaxial tests on undisturbed and re-molded clay and silty clay soils taken from three trial sites in Central England. The samples were loaded incrementally, using 1000 cycles of load at a frequency of $2 \mathrm{~Hz}$ at each increment, and both resilient and permanent strains were measured both across the samples and using on-sample gauges. The paper concludes by drawing together the needs of the specification approach and the material behavior with key correlations observed in the laboratory work, and thereby proposes a way forward for a simplified analytical performance-based pavement foundation design process.

\section{A PERFORMANCE SPECIFICATION FOR PAVEMENT FOUNDATIONS}

For a pavement foundation to perform adequately it must fulfill the following three functions:

1. It must support a limited number of construction vehicles during the construction of overlying layers. The foundation must not deform sufficiently (i.e. undergo resilient deformation) under trafficking so as to reduce the effectiveness of the compacted structure and it must dissipate the high stresses applied by the wheels (directly on the foundation) to a sufficiently low level to ensure that the subgrade does not sustain significant permanent deformation (rutting).

2. It must provide an adequate base for the placing and compaction of the overlying layers (i.e. it must not undergo large resilient deformations under the action of the very high compaction stresses such that it reduces the effectiveness of the compacted structure of the overlying layer(s)). 
3. It must provide adequate support to the overlying bound layers when the road pavement is inservice, and distribute the very large number of (lower) stresses transmitted through the bound layers to reduce the applied stress to the subgrade to a sufficiently low level. If it does not, flexural fatigue cracking of the upper layers can initiate and propagate and/or the progressive accumulation of permanent strain (rutting) may lead to deterioration of the complete pavement.

In addition, the materials used must possess chemical and physical stability in the long-term and the overlying materials must provide frost resistance to the subgrade. Conditions one and two are short-term construction conditions featuring relatively few passes of high applied stresses. Condition three is a long-term design requirement to resist many millions of lower stress applications over many years and therefore the foundation materials will progressively alter due to loading history and (especially) drainage.

To perform these functions the pavement foundations must possess the two primary performance parameters of adequate stiffness (i.e. resilient elastic modulus) and resistance to permanent deformation. Therefore to assess such performance within a performance-based specification, the following must be available:

1. an ability to measure the performance parameters of the subgrade in the laboratory for both the short-term construction condition and the long-term in-service condition,

2. a method of predicting accurately the environmental changes in the pavement over the long-term,

3. a means of incorporating the measured parameters in the design process, and

4. an ability to measure the same parameters for the subgrade and pavement foundation layers in the field to assess compliance, and the setting of suitable target values for construction to provide assurance of the quality of the final product.

This in turn requires the assessment of both the resilient elastic modulus and resistance to permanent deformation of the materials individually and as a composite for the construction and the in-service conditions. The final requirement has been addressed elsewhere (Fleming and Rogers, 1995; Fleming et al, 2001), whereas the former three requirements are addressed herein. The ability to model, and thus predict, changes 
in material performance due to environmental changes within the pavement (item 2 above), linked mainly to suction and water content variations, requires significant research to be fully developed. Some of the issues are briefly discussed in Section 3.5, but space precludes full consideration of this herein.

\section{PERFORMANCE OF FINE GRAINED AND GRANULAR MATERIALS SUBJECT TO VEHICULAR LOADING}

\subsection{Pavement Loading}

The stress pulse generated when a vehicle wheel travels across a pavement consists of vertical and horizontal stress components with an approximately sinusoidal (double) pulse of shear stress (Brown, 1996). This stress pattern subjects an element within the pavement to a rotation of principal stresses (as opposed to a reversal in the shear stress caused by the application of a pulsed vertical load). Obviously this pulse varies with the speed, load and direction of the vehicle, and becomes repetitive with the passage of more wheels. Current foundation design for construction trafficking assumes 1000 passes of a standard axle (Powell et al 1984).

Generally the lower the element of interest in a pavement, the lower the applied stress, due to the load distribution capabilities of the layered structure. Measurements in trial pavements (reviewed by Brown, 1996) have shown that the passage of a loaded wheel on a $165 \mathrm{~mm}$ thick asphalt pavement (supported on 150mm of granular material) causes a subgrade stress of $15 \mathrm{kPa}$ with a pulse duration of approximately 0.6 seconds, whereas a subgrade stress pulse beneath a $350 \mathrm{~mm}$ granular haul road is approximately $100 \mathrm{kPa}$ with a pulse duration of approximately 1 second. Thus the stresses experienced by the pavement foundation during construction are much higher than those in the completed pavement and this will significantly affect material response.

\subsection{Performance of Pavement Materials Under Repeated Loading}

When pavement materials are subjected to a cycle of stress they sustain deformations (i.e. strains) which consist of resilient and permanent components. The magnitude of each of these deformations defines the per- 
formance parameters of the materials. The resilient elastic modulus is calculated from the resilient strain and the change in stress, usually measured on unloading. The permanent strain is found from the permanent change in dimension (i.e. length of an element), and progressively increases under repeated stress cycles. There are many factors that affect the magnitude of each of these strains, and consequently the material performance in a pavement. Some of the properties for both fine-grained and granular materials significant to the proposed design method (Section 7) are summarized below.

\subsubsection{The Behavior of Fine-Grained Soils Under Repeated Loading}

The resilient elastic modulus of cohesive, fine-grained soils decreases non-linearly with increasing applied stress, when all other factors are kept constant (Seed et al, 1962). Materials exhibiting high suctions (negative pore water pressures) have been shown to have higher resilient moduli, indicating stiffness to be a function of three stress variables: the confining stress, the axial stress and the matrix suction of the materials (Cheung, 1994). Significantly no changes in resilient response with changing axial stress frequency have been observed.

At low deviator stress levels permanent deformation has been shown to increase with the logarithm of the number of cycles, the rate of accumulation of permanent strain increasing as the stress increases. This eventually leads to a deviator stress level, denoted the 'threshold stress' ( qthreshold $_{\text {), }}$ under which the rate of accumulation of deformation increases exponentially. This response has been shown to be related to the material's stress history and water content, and thus shear strength. Brown (1996) therefore suggested that the dominant factor in determining permanent deformation is the relationship between applied shear stress (q) and the shear strength of the soil (i.e. stress ratio, $\mathrm{q} / \mathrm{q}_{\max }$ ).

Cheung (1994) suggested the concept of a limiting value of $\mathrm{q} / \mathrm{q}_{\max }$ (i.e. $\mathrm{q}_{\text {threshold }} / \mathrm{q}_{\max }$ ) above which plastic deformation increases relatively rapidly. According to this relationship, the accumulation of permanent strain should be approximately linear with the logarithm of the number of load applications for stress ratios that lie below the threshold stress ratio. If $q$ becomes greater than $\mathrm{q}_{\text {threshold, }}$, then the permanent strain increases at a markedly increased rate. Brown and Dawson (1992) suggest that for design purposes this threshold should be 
taken at a deviator stress equivalent to $50 \%$ of the soil's measured suction. In contrast Cheung (1994) suggested that the threshold stress occurs at the deviator stress required to generate $1 \%$ permanent strain in a sample following 1000 applications.

\subsubsection{The Behavior of Granular Materials Under Repeated Loading}

Hicks and Monismith (1971) showed that the principal factor influencing the measured resilient properties of granular materials is the stress level. The modulus ( $\mathrm{M}_{\mathrm{r}}$ measured in a triaxial cell) was shown to increase significantly with increasing confining pressure and slightly with increasing repeated deviator stress, as long as shear failure was not approached. The following simple relationship to predict material behavior (known as the $\mathrm{K}-\theta$ model) was proposed:

$$
\mathrm{M}_{\mathrm{r}}=\mathrm{K}_{1} \theta^{\mathrm{K} 2}
$$

where $K_{1}$ and $K_{2}$ are material parameters, and $\theta$ is the sum of the principal stresses $\left(\sigma_{1}+2 \sigma_{3}\right)$. This formula, although describing the general behavior of granular materials, cannot be used to predict precise behavior during loading and other more complex models have been proposed. Nevertheless, the K- $\theta$ model is regarded as an adequate simplification for design purposes where other factors, such as adjacent material and layer parameters, affect response (Brown, 1996).

Permanent deformation in granular materials has been shown to increase proportionally with the logarithm of the number of cycles of applied stress (Barksdale, 1972). Similar to fine-grained materials, a limiting deviator stress below which permanent deformation remains stable has been identified: $70 \%$ of failure stress has been suggested as a threshold stress (Boyce et al, 1976), although research to define the boundary between stable and unstable accumulation of permanent strains in granular materials under cyclic loading, more recently referred to as the shakedown limit (Lekarp and Dawson 1998), continues.

\subsection{Composite Performance of Materials in a Pavement Foundation}

Much research has concentrated on defining the factors that affect the individual material behavior as described above. However, the interaction between the sub-base/capping materials and the subgrade (composite 
behavior) is also of crucial importance for pavement foundation design. The interaction between two layers of material, having different threshold stress ratios and elastic moduli, under transient loading produces a major influence on how each layer and type of material can act. If an unbound granular material overlying a softer, weaker subgrade is subjected to loading, the deflections will be partially controlled by the upper layer as a result of its load spreading ability (modulus). This controls the level of stress transmitted to the subgrade. However, the subgrade will influence the amount of load spreading that can take place by the way in which it reacts to the stress that is transmitted. Thus the layer interaction affects the stress distribution, which in turn affects the total elastic and plastic strains that are developed within each material, hence their response to those stresses and vice versa (Fleming and Rogers, 1995). This behavior ultimately leads to permanent deformation (rutting) within the pavement.

The stiffness of pavement foundation materials clearly varies with the degree of confinement and the applied stress. Therefore the properties of an element within any one layer of material in a pavement structure will vary with the magnitude of the applied stress, the relative position of the element to the stress, and the confinement provided the thickness of the layer and the pavement structure as a whole (Fleming and Rogers, 1995).

\subsection{Currently Used Laboratory Assessment Methods for Pavement Material Performance Assessment}

Sophisticated Repeated Load Triaxial Test (RLTT) procedures with on-sample instrumentation have been developed to assess both stiffness and permanent deformation behavior of clay soils. However, due to the nature of the apparatus required, such testing has so far been limited to research laboratories. Whilst it is accepted that the RLTT does not subject materials to a rotation of principal stress, and thus underestimates permanent deformation, the assessment of threshold stress is possible. The RLTT has been suggested as the most appropriate apparatus currently available to assess parameters for design and was used to provide data for this research. The performance of granular materials can also be determined using the RLTT, although significant research challenges for granular materials with large particle sizes remain. Dynamic plate testing may offer a way forward for the assessment of design parameters for such materials (Frost et al, 2001). 


\subsection{Prediction of Environmental Changes within a Pavement and their Modeling}

Changes in the environmental conditions, in both the short-term and long-term, will influence material performance. While road foundation design is based primarily on construction loading, it is essential to consider long-term behavior and potential environmental changes, for example where pavement foundations are partially constructed and left for some months before they are completed. In addition, the material characteristics at the construction stage affect the nature of the material's changes, and hence their long-term behavior, due to the hysteresis effects associated with changes in suction.

Equilibrium water content is reached after the equilibration of (usually dissipation of negative) pore water pressures in the subgrade. This equilibrium value, once attained, remains relatively stable under impermeable pavements. Equilibrium water content has therefore been used for long-term design (Croney, 1997; Black and Lister, 1979). Factors such as a lowering of the water table (due to the early installation and effectiveness of sub-surface drainage), changes to the stress history of materials (due to the removal of overburden in cuttings or additional stresses due to pavement construction), changes to the material structure (due to the construction operations), material type, temperature, humidity and rainfall may all result in changes to the material's suction (which controls the equilibrium water content), and hence the material's mechanical performance due to its direct influence on the mean normal effective stress (Black and Lister, 1979). Although these factors primarily affect the subgrade, capping and sub-base can also be affected, especially if wet weather occurs during construction.

The effects of changes in suction (hence subgrade water content) on pavement performance are difficult to predict. Several authors have monitored the change in pavement performance with season, although mainly in tropical and cold climates where the environmental variations are greater than in the temperate UK (e.g. Basma and Al-Suleiman, 1991; Andrew et al, 1998). In the UK, seasonal changes to the level of the water table have been shown to influence the strain response of clay subgrades under load (Sha'at et al, 1992; Kamal, 1993). This is normally of little significance for a full pavement construction as long as the granular 
layers are adequately drained and 'worst case' subgrade design parameters are used. However, it can be important at the construction stage where applied stresses are far higher, hence lower subgrade stiffness is experienced. To enable this effect to be assessed, the changes in water content must be predicted. (Fleming et al, 1998).

The problems of (highly) variable weather and predicting sub-surface water regimes and material response make it difficult to anticipate the long-term changes to the performance of unprotected or partially completed pavement foundations. In addition, measurements of subgrade performance during construction will be influenced by temporary changes caused by drying and re-wetting, as well as surface remolding (under tire action), re-grading and re-compaction. These changes to the materials' structure and water content make it very difficult to propose a target subgrade modulus for site measurements to confirm the laboratory values of modulus used for the subgrade in design.

\subsection{Modeling Field Conditions and Sample States in the Laboratory}

For accurate laboratory testing the subgrade's condition must be modeled while allowing for changes in its compacted state, environmental conditions (hence water content), applied loading (depending on the construction operations performed), and its location (cutting or embankment). There are four material states that should be considered:

1. Undisturbed soil, as found in the base of cuttings or 'at grade' at the time of construction.

2. Remolded, re-compacted soil at the in-situ water content, as found in embankments at the time of construction or after reworking.

3. Undisturbed soil, but at its long-term equilibrium water contents after equilibration.

4. Remolded, re-compacted soil, but at its long-term equilibrium water contents after equilibration.

The undisturbed samples can be prepared directly from the subgrade, while remolded samples can be straightforwardly prepared by re-compacting a sample of the subgrade using appropriate compaction meth- 
odologies. To create samples that accurately represent the equilibrium condition, however, the prepared sample (either undisturbed or remolded) should be allowed to change water content under the equivalent conditions of confining stress and suction that would be experienced in the field. Various authors have proposed methods of forcing water into pre-compacted (i.e. remolded) samples (e.g. Chu et al, 1977; Drumm et al, 1997). They state that the soil requires a considerable time to equilibrate, even for high permeability soils. UK subgrades are typically low permeability clay soils and for a commercial test, as would be required to provide data for a performance-based design, such a lengthy procedure would prove impractical. The difficulty of bringing undisturbed samples to equilibrium would be greater. In addition, it has been found that when water was forced radially into a clay under a back pressure in an attempt to reduce the preparation time, considerable softening of the outside of the specimen occurred with very little water penetration to the center such that an even water distribution could not be achieved.

\section{REPEATED LOAD TRIAXIAL TESTING METHODOLOGY}

\subsection{Materials Tested}

To determine the performance parameters for a range of typical UK clay subgrades, over sixty repeated load triaxial tests have been carried out on samples retrieved from three purpose-built field trials and various live road construction projects. Manually driven $100 \mathrm{~mm}$ diameter (U100) undisturbed samples and bulk soil samples were taken from the sites and were tested in a variety of states to model the conditions anticipated over the life of a pavement foundation.

Nine U100 samples were taken from an area 5m wide by 30m long at a trial site at Hathern, Leicestershire. The subgrade consisted of a firm/stiff sandy silty CLAY, with silt partings, the clay becoming more sandy with depth, overlying a wet silty sand. Samples were taken above the interface between the clay and the sand. The Atterberg Limits ( $\mathrm{LL}=27-36 \%, \mathrm{PL}=15-20 \%)$ and natural water content $\left(\mathrm{w}_{\mathrm{nat}}=15-23 \%\right)$ were used to predict the equilibrium water content ( $\left.\mathrm{w}_{\text {eqm }}=10-16 \%\right)$. Samples from the $\mathrm{A} 1(\mathrm{M})$ motorway, near Peterborough, consisted of Oxford Clay ( $\mathrm{LL}=40 \%, \mathrm{PL}=25 \%, \mathrm{w}_{\text {nat }}=22 \%, \mathrm{w}_{\text {eqm }}=24 \%$ ), with some fine (2-6 
$\mathrm{mm}$ ) gravel and occasional stones (20-25 mm). A further trial site at Bardon, Leicestershire, consisted of a firm slightly gravely sandy silty CLAY with silt partings ( $\left.L L=46 \%, P L=22 \%, w_{\text {nat }}=19 \%, w_{\text {eqm }}=23 \%\right)$.

\subsection{Apparatus and Methodology}

Nottingham University’s RLTT equipment, a prototype developed as a possible commercial test apparatus (Cheung, 1994), was used. The $100 \mathrm{~mm}$ diameter, $200 \mathrm{~mm}$ long samples were fitted with two on-sample strain measurement loops which measured the vertical strain over the middle third of the sample, thus removing end restraint effects caused by the load platens. The resilient strain was taken as the average of the readings from the on-sample gauges. A linear variable differential transformer (LVDT) was fitted to the upper load platen to measure total sample strain. The sample was tested with a cell pressure of $20 \mathrm{kPa}$ to simulate the confining stress beneath a typical road pavement structure and subjected to an axial seating stress of 5 $\mathrm{kPa}$. Sets of 1000 cycles of deviator stress, increased in $10 \mathrm{kPa}$ increments, were applied at a frequency of 2 Hz. At 5\% cumulative permanent axial strain the cyclic loading was stopped and the sample loaded monotonically to failure. The resilient modulus was calculated from the 999th cycle of each deviator stress increment, with the final 10 cycles at each stress increment being investigated to ensure that the 999th cycle was representative. Permanent strains were calculated from the cumulative strain sustained by the specimen measured at completion of each set of deviator stress cycles. Deformations were measured concurrently, rather than on separate samples as is frequently undertaken, because the variability of undisturbed samples was considered to be a problem when trying to link stiffness and permanent deformation response, particularly at very low values of deviator stress. As long as stress is increased incrementally (and stiffness is measured on unload) the previous permanent deformation will be generated by a stress lower than the current stress level and stiffness is not linked to stress history, therefore previous loading to lower stress was not considered to be adversely influential.

\subsection{Sample Preparation}

Undisturbed samples were prepared directly from the U100 samples by extrusion and trimming. Remolded samples at the in-situ water content were prepared from soil broken up in a mixer to form lumps $<5$ mm in size and compacted in a $100 \mathrm{~mm}$ diameter, $250 \mathrm{~mm}$ high Procter compaction mould in five equal lay- 
ers using a $2.5 \mathrm{~kg}$ hammer falling through $300 \mathrm{~mm}, 27$ blows being applied to each layer (BSI, 1990). The equilibrium remolded samples were manufactured by mixing sufficient water to raise the water content to that predicted using the Black and Lister (1979) method (i.e. $\mathrm{w}_{\text {eqm }}$ ) into the remolded sample prior to compaction, which was carried out as described above. It should be noted that sample behavior would be different than if the samples had been remolded and then brought to equilibrium, primarily because the additional water will alter the efficacy of compaction. Nevertheless it was considered that this remolding to equilibrium, as is allowed for in conventional CBR design, should be a 'worst case equilibrium condition' for design. No equilibrium undisturbed samples were created, by allowing undisturbed $\mathrm{U} 100$ samples to wet up to $\mathrm{w}_{\text {eqm }}$, due to the difficulties of water content prediction and non-uniformity described earlier.

\section{TRIAXIAL TESTS DATA}

Figures 1 and 2 show typical resilient modulus and permanent strain data for a series of the samples tested. Corresponding data for each sample are plotted in the two figures and all exhibit similar patterns of behavior. As expected for clay subgrades, the resilient strain data exhibit inverse stress dependency (the higher the value of cycled deviator stress, the lower the modulus) until an approximately constant modulus (for that sample) is reached at higher stress levels, this value being termed the 'stiffness asymptote'. The permanent strain exhibits direct stress dependency (the lower the applied stress, the lower the permanent strain). Initially the permanent strain increases only slightly, but as the deviator stress continues to rise the permanent strain increases exponentially beyond a point considered to be the 'threshold'.

Similar patterns of resilient and permanent strain behavior were seen for all samples, although the stresses at which the stiffness asymptote and threshold stress were reached were different for each sample. Similar materials at similar water contents were found to have similar stiffness asymptotes and threshold stresses despite their behavior at lower stress being significantly different. Considerable variability was observed in data recorded from samples taken from small areas of the same sites, particularly at lower applied stress, and this 
is a potential concern if such strain data are used for design. However at higher stresses this variability is greatly reduced.

Figure 3 shows typical sets of resilient modulus data for two undisturbed soils. The data are broadly as expected, with the two on-sample strain gauge curves (OS1 and OS2) showing similar trends, albeit slightly different values probably due to slightly different material properties across the sample (as indeed were noted in the case of the A1M sample, with evidence of gravel and associated small voids along one side after sample extrusion explaining the initial differences in moduli). In addition the means of strain data collection could contribute to differences when attempting to measure very small resilient strains using gauges that need to measure over a comparatively large permanent strain range. This is not related to the type of gauges used, but to the ability of a 16 bit analogue to digital (A to D) converter to measure a very small resilient strain in a unit calibrated to cover a large strain range (i.e. the magnitude of strain associated with 1 digital bit is relatively large compared to the measurement).

The resilient modulus curve determined from the total sample strain lies below those for the on-sample strain gauges, indicating that the measured strains were greater. Conventional thinking would suggest the reverse, i.e. that the strain in the middle portion of the sample would be greatest due to the lack of restraint from the load platens. However at low deviator stress levels the deformation caused to the sample is very small and is extremely sensitive to areas of lower stiffness, such as could occur due to disturbance at the ends of the sample during sample preparation. At higher deviator stresses, once higher permanent strains have been induced, A to D converter precision is no longer an issue and the moduli calculated from the transducers converge to form a stiffness asymptote.

It should be noted that the studs used to connect the strain gauges to the sample are pushed in manually, which results in some local disturbance. Where the sample contains gravel, significantly greater internal sample disturbance will occur if the studs hit the gravel particles during insertion and it is likely that a poor connection will occur between the sample and the strain gauge loop. As the sample sustains permanent deformation the soil will consolidate around the studs and improve the fixing of the strain gauges. The use of 
conditioning, if carried out at a high enough deviator stress, would cause significant permanent deformation and therefore improve these connections and end disturbance problems (and is commonly used), although the conditioning will also affect the sample response. The tests revealed that reasonable convergence between the various gauge readings on any one sample was reached at resilient strain levels of approximately $0.3 \%$, but that material variability at any site (Figure 1) was independent of strain level.

The prediction of $\mathrm{w}_{\text {eqm }}$ presents significant problems for mixed soils since it is based on the measured plasticity of the fine fraction of a soil only. Thus for soils that contain a granular fraction, which is removed for the plasticity tests, the calculation of $\mathrm{w}_{\text {eqm }}$ is distorted. For example, the predicted (Black and Lister, 1979) value of $\mathrm{w}_{\text {eqm }}$ for the Hathern was lower than the natural value $\left(\mathrm{w}_{\text {nat }}\right)$. It is consequently extremely difficult to make an accurate allowance for this discrepancy.

Figures 4 and 5 show the behavior of two samples prepared in the three states described in Section 4.3. The Bardon sample contained a number of wet silty bands. When the soil was remolded these weak zones were redistributed throughout the sample resulting in a significant improvement in overall sample strength and stiffness. When the additional water to reach $\mathrm{w}_{\text {eqm }}$ was added the sample strains increased as expected, in this case approximately to the level of the undisturbed sample. If the increase in water content had not been combined with a destruction of the soil structure (i.e. an undisturbed sample wetted to equilibrium had been created) it is likely that the sample would have exhibited a much more rapid accumulation of permanent strain and a lower resilient modulus than the mixed soil.

The A1(M) sample had a more homogenous clay structure. Figures 4 and 5 show that the remolded sample exhibits similar permanent strain but lower resilient strain (thus higher modulus) than the undisturbed sample. In this latter respect the behavior again contradicts conventional thinking and is probably due to either the destruction of fissures, which can be found in the natural soil, or effects of compaction and shearing of the over-consolidated clay. The equilibrium sample shows a reduction in modulus, as expected. 


\section{THRESHOLD STRENGTH AND ASYMPTOTIC STIFFNESS}

Two approaches were used to determine threshold stress from the permanent strain readings, i.e. defining the threshold as either the deviator stress at which 1\% permanent strain was reached (after Cheung, 1994) or the point of maximum curvature in the curves of permanent strain against deviator stress. Threshold stresses defined in these two ways are plotted against the respective samples' undrained shear strength in Figure 6 and are shown to be comparable, the lines of best fit giving similar lines of correlation.

Figure 6 also includes two lines to illustrate an approach using shear strength to define threshold similar to that suggested for railways and to the suction approach suggested by Brown and Dawson (1992). The first line represents a definition of the threshold stress as being equal to $0.5 q_{\max }$, i.e. $50 \%$ of the deviator stress at failure or the undrained shear strength $\left(\mathrm{c}_{\mathrm{u}}\right)$ of the sample, and gives a line remarkably similar to the correlation lines for the two strain approaches. The second line shown in Figure 6 is a suggested conservative design threshold approach at $0.25 q_{\max }$ (i.e. threshold stress equal to $0.5 c_{u}$ ). This line lies below the majority of the data points and should therefore give confidence that if applied subgrade stress is maintained below this level, the permanent deformation sustained should not become unstable and result in rut formation. These data further suggest the potential benefit of controlling trafficking during capping placement (i.e. before the full capping thickness is placed) to limit potential cumulative deformation in the subgrade. In addition, if the foundation is to be used as a haul route the benefit of early installation of sub-base to provide additional thickness will reduce subgrade stress and hence limit subgrade deformations.

Figure 7 shows the resilient moduli at a deviator stress of $0.5 q_{\max }$ compared to the 'asymptotic stiffness' values determined from the graphs of resilient modulus against deviator stress. A linear relationship with a strong correlation over a broad range of sample stiffnesses is evident. This suggests that when a sample has reached the threshold stress (i.e. the point at which the development of permanent strain is becoming unstable), the resilient modulus is at or approaching a constant (lower bound) value at which the resilient strain is directly proportional to applied stress, hence giving the stiffness asymptote described earlier. 


\section{IMPLICATIONS FOR A PERFORMANCE-BASED FOUNDATION DESIGN}

From Section 3 and the threshold stress assessed in Section 6 it can be seen that permanent deformation of the subgrade can be controlled by limiting the applied vertical stress, transmitted through the overlying layers, to a level below that causing an exponential increase in the accumulation of permanent deformation (i.e. below the threshold stress). It is clear, however, that the current lack of a routine test to measure the required performance parameters is restrictive to the development of analytical design using full performance assessment; sophisticated testing (using the RLTT or equivalent) is required to determine appropriate subgrade and foundation material properties under appropriate applied stress conditions and realistically this is currently limited to research laboratories.

If the threshold stress can be derived by alternative means (e.g. as a proportion of $\mathrm{q}_{\max }$ or otherwise) then only the resilient modulus and stress dependency of the pavement materials need to be measured for use in an analytical pavement design, based on limiting the transmitted subgrade stress. Such a design then only needs to consider permanent deformation as a function of strength and material stiffness based on limiting applied stresses through the composite foundation structure (assuming the capping and sub-base have sufficient strength to avoid internal permanent deformations). Such an approach forms the basis for the method of determining the design thickness of the unbound layers for UK railway track (Heath et al, 1972), in which RLTT data were used to define a limiting stress (i.e. $0.5 q_{\max }$ ) that was then related to empirically measured/observed field performance. Although acknowledged as a simplification, it has been considered to provide practical guidance for design. This approach could clearly not be translated to other applications, such as road foundations, without extensive and fundamental work to prove its relevance under accurately applied stress conditions and/or via extensive field observations.

The threshold relationships shown in Figures 6 and 7 suggest a potential way forward for analytical design. If the undrained strength of clay subgrade samples can be accurately measured, this can be related to a limiting allowable applied subgrade stress via the threshold stress / shear strength relationship defined in Figure 6. This limit can then be applied in design for the 'worst case' construction condition, i.e. to design the 
foundation for construction trafficking. It is suggested that resilient moduli (and clay subgrade stress dependency) could be assessed simply within a standard triaxial cell using monotonic loading and unloading, as stiffness in general is not significantly load rate or stress history dependent. Alternatively, a single value of resilient modulus measured at threshold stress (the 'asymptotic stiffness') should be appropriate for shortterm construction design. These subgrade data could then be coupled with the stress dependency of the overlying granular materials, potentially measured via dynamic plate tests or determined using standard relationships derived from a K- $\theta$ model. Simple analysis to derive foundation thickness can then be performed using iterative elastic analysis.

For example the soil sample from the Bardon site (the RLTT data for which are plotted in Figures 4 and 5) has a shear strength of $48 \mathrm{kN} / \mathrm{m}^{2}$ in its undisturbed state, $65 \mathrm{kN} / \mathrm{m}^{2}$ in its remolded state and $48 \mathrm{kN} / \mathrm{m}^{2}$ in its equilibrium remolded state, with corresponding resilient moduli (or 'stiffness asymptotes') for the three states of 12, 16 and 10 MPa respectively. Assuming a back-analyzed stress dependency for granular materials using the $\mathrm{K}-\theta$ model of $5.2 \mathrm{~K}^{0.6}$, the thickness of granular material required to control applied subgrade stress can be found by elastic analysis and limited to a value suggested by the threshold stress correlation defined above and shown in Figure 6. For this example the subgrade stress should be maintained below $24 \mathrm{kN} / \mathrm{m}^{2}$ for the 'worst case' construction and long-term conditions respectively (assuming a $500 \mathrm{kPa}$ wheel stress), requiring a granular material thickness of approximately $400 \mathrm{~mm}$. Trafficking of trial pavement foundations constructed at this site showed that the pavement performed acceptably when $400 \mathrm{~mm}$ of granular material was provided. In addition, back-analysis of field trial rutting data on other trials constructed with standard granular materials (Frost, 2000) has indicated that where the applied subgrade stress was below 0.5 qmax, limited rutting, i.e. within currently permitted limits (Powell et al, 1984), was observed at the surface. Backanalyzed designs for these same data using the above method, together with (field derived) granular material stress dependency, gave comparable foundation thickness to conventional CBR based designs. However it should be noted that designs using this method are reliant on appropriate granular material stress dependency data and the production of such data reliably and routinely is an area requiring further work. 
For the longer-term service condition it is anticipated that the subgrade will have reduced in strength due to equilibration of pore water pressures (i.e. dissipation of suctions, in spite of the fact that drainage will have become effective and, ideally, some small level of suction will be retained). However when the pavement is in service the stress applied to the subgrade is much lower, thus the subgrade stiffness is higher, and consequently the use of a short-term (lower) asymptotic stiffness should potentially still be conservative for design. While further work is required to confirm the applicability of this assumption, the data collected in this study indicate that it could offer an engineering solution to dealing with long-term conditions. The more significant challenge, if this approach is to be used routinely, is in predicting an appropriate value of 'worst case' construction water content conditions.

\section{CONCLUSIONS}

To facilitate implementation of a performance-based approach to pavement foundation design, a test is required to measure resilient modulus of the subgrade at expected equilibrium conditions. The RLTT appears to be the most appropriate. However testing has revealed significant problems. In particular a suitable method of varying the water content of, especially, clay soil to represent dissipation of suctions in subgrades for inservice pavement structures is required for routine testing, as well as a suitable method of predicting change in water content over time. The method chosen must be such that it does not cause an (unrealistic) improvement in the properties of mixed or fissured soils.

Significant problems were encountered when measuring small strains under low applied deviator stresses in unconditioned samples. The calculation of resilient modulus at low deviator stresses is highly sensitive to small differences in strain, which leads to large apparent variation between test data. In addition, soil variability results in difficulties in obtaining representative design values, not only between test samples, but also across any one sample. 
Remolding and re-compaction of soil leads to a destruction of soil structure or fabric. This process will redistribute weak, or strong, materials and water to create a homogeneous sample, which affects compaction and subsequent test behavior.

The maximum stress experienced by a subgrade, excepting perhaps that due to compaction of the materials itself (which does not cause damage), occurs during construction trafficking and this is the 'worst case' for design. Therefore design to limit permanent deformation during construction is the primary design case. Long-term service conditions will not be so onerous, even though the performance of the subgrade will often be adversely affected by the loss of suctions as the equilibrium water content is established, since the stresses transmitted to the subgrade through the structural pavement layers will be far lower.

To control permanent deformation within a pavement the materials used must have sufficient strength and have adequate stiffness (or resilient elastic modulus). These two properties combine to give a composite foundation within a complete pavement that can dissipate applied stresses to a sufficiently low level such that excessive permanent and transient deformations will not occur.

A value of applied cyclic deviator stress above which the onset of permanent deformation becomes unstable is shown to occur approximately at $50 \%$ of the deviator stress at failure $\left(0.5 q_{\max }\right.$, or $\left.c_{u}\right)$. The resilient modulus at a deviator stress of $0.5 \mathrm{q}_{\max }$ is shown to be approaching a minimum (i.e. a 'stiffness asymptote'). This suggests that for fine-grained materials where permanent strain is becoming unstable, stiffness is tending to a constant value.

A simplified design approach is suggested whereby subgrade stress is limited based on threshold stress, which is assessed from a correlation with shear strength. Preliminary designs with this method have given values comparable to conventional design, but are more soundly based. 


\section{ACKNOWLEDGEMENTS}

The authors are grateful to Scott Wilson (Pavement Engineering) Ltd. and Nottingham University for their collaboration on this work, and to the UK Highways Agency for funding the research. The opinions expressed are those of the authors and not necessarily those of the UK Highways Agency.

\section{REFERENCES}

Andrew, J.W., Jackson, N.M. and Drumm, E.C. 1998. Measurement of Seasonal Variations in Subgrade Properties. Application of Geotechnical Principles in Pavement Engineering. Geocongress, October. Boston, USA (ASCE Special Publication), pp. 13-38.

Barksdale, R.D. 1972. Laboratory Evaluation of Rutting in Base Course Materials. Proceedings, 3rd International Conference on Asphalt Pavements. University of Michigan, Ann Arbor, USA, pp. 161-174.

Basma, A.A. and Al-Suleiman, T.I. 1991. Climatic Considerations in New AASHTO Flexible Pavement Design. Journal of Transportation Engineering, Vol. 117, No. 2, pp. 210-223.

Black, W.P.M and Lister, N.W. 1979. The strength of Clay Fill Subgrades: Its Prediction in Relation to Road Performance, Transport and Road Research Laboratory Report LR889, Crowthorne, Berkshire, UK.

Boyce, J.R., Brown, S.F. and Pell, P.S. 1976. The Resilient Behaviour of a Granular Material Under Repeated Loading. Proceedings of the Australian Road Research Board (ARRB). Vol. 8, Sydney, Australia, pp. 8-19.

British Standards Institution. 1990. BS 1377, Part 4, British Standard Methods of Test for Soils for Civil Engineering Purposes, Compaction Related Tests, HMSO, London, UK. 
Brown, S.F. 1996. Soil Mechanics in Pavement Engineering. 36th Rankine Lecture of the British Geotechnical Society. Geotechnique, Vol. 46, No. 3, pp. 383-426.

Brown, S.F. and Dawson, A.R. 1992. Two Stage Mechanistic Approach to Asphalt Pavement Design. Proceedings of the 7th International Conference on Asphalt Pavements, Vol. 1. International Society for Asphalt Pavements, University of Nottingham, Nottingham, UK, pp. 16-34.

Cheung, L.W. 1994. Laboratory Assessment of Pavement Foundation Materials. Ph.D. Thesis, University of Nottingham, Nottingham, UK.

Chu, T.Y., Humphries, K.W., Stewart, R.L., Guram, S.S. and Chen, S.N. 1977. Soil Moisture as a Factor in Subgrade Evaluation. Transportation Engineering Journal, ASCE, Vol. 103, January, pp. 87-102.

Drumm, E.C., Reeves, J.S., Madgett, M.R. and Trolinger, W.D. 1997. Subgrade Resilient Modulus Correction for Saturation Effects. Journal of Geotechnical and Geoenvironmental Engineering, ASCE, Vol. 123, July, pp. 663-670.

Fleming, P.R. and Rogers, C.D.F. 1995. Assessment of Pavement Foundations During Construction. Transportation, Proceedings of the Institution of Civil Engineers, Vol. 111, No. 2, pp. 105-115.

Fleming, P.R., Rogers, C.D.F., Dawson, A.R. and Frost, M.W. 1998. Subgrade Equilibrium Water Content and Resilient Modulus for UK Clays. Proceedings of the International Symposium on Subdrainage in Road Pavements and Subgrades. World Road Association, Granada, Spain, pp. 359-366.

Frost, M.W. Fleming, P.R., and Rogers, C.D.F. 2001. Assessment of a Performance Specification Approach to Pavement Foundations. Transportation Research Record 1757, Soils Geology and Foundations. TRB Washington pp 100-108. 
Frost, M.W. 2000. The Performance of Pavement Foundations During Construction. Ph.D. Thesis, Loughborough University, UK.

Heath, D.L, Shenton, M.J., Sparrow, R.W. and Waters, J.M. 1972. Design of Conventional Rail Track Foundations. Proceedings of the Institution of Civil Engineers. Vol. 51, pp. 251-267.

Hicks, R.G. and Monismith, C.L. 1971. Factors Influencing the Resilient Response of Granular Materials. Highways Research Report 345. Highways Research Board, pp. 15-31.

Kamal, M.A. 1993. Behaviour of Granular Materials used in Flexible Pavements. Ph.D. Thesis, The Queens University, Belfast, UK.

Lekarp, F. and Dawson, A.R. 1998. Modelling Permanent Deformation Behaviour of Unbound Granular Materials. Construction Building Materials, Vol. 12, No. 1, pp. 9-18.

MCHW 1994. Specification for Highway Works. Manual of Contract Documents for Highway Works, Vol. 1, HMSO, London, UK.

Powell, W.D., Potter, J.F., Mayhew, H.C. and Nunn, M.E. 1984. The Structural Design of Bituminous Roads (LR1132). Transport Research Laboratory, Crowthorne, Berkshire, UK.

Seed, H.B., Chan, C.K. and Lee, C.E. 1962. Resilience Characteristics of Subgrade Soils and Their Relation to Fatigue Failures in Asphalt Pavements. Proceedings of the International Conference on the Structural Design of Asphalt Pavements. University of Michigan, Ann Arbor, USA, pp. 611-636.

Sha'at, A.A., Kamal, M.A. and Matter, N.S. 1992. Relationship between Climatic Conditions and the Structural Parameters of Flexible Pavements. Proceedings of the 7th International Conference on Asphalt Pavements. International Society for Asphalt Pavements, Nottingham, UK, Vol. 4, pp. 326-340. 


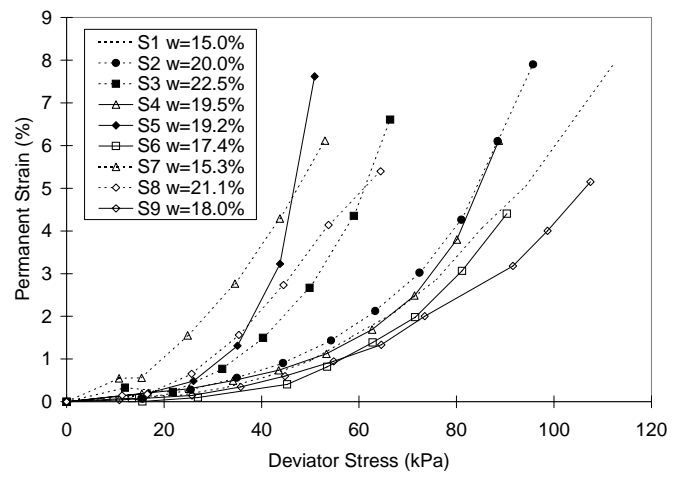

Figure 1. Typical Relationships between

Permanent Strain and Deviator Stress. 


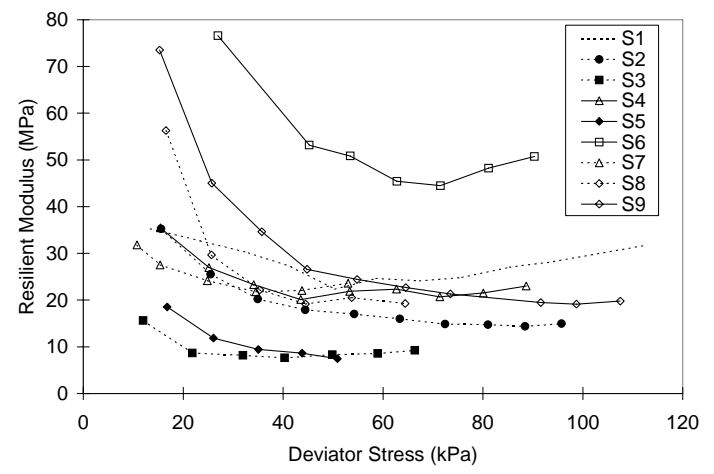

Figure 2. Typical Relationships between Resilient Modulus and Deviator Stress. 


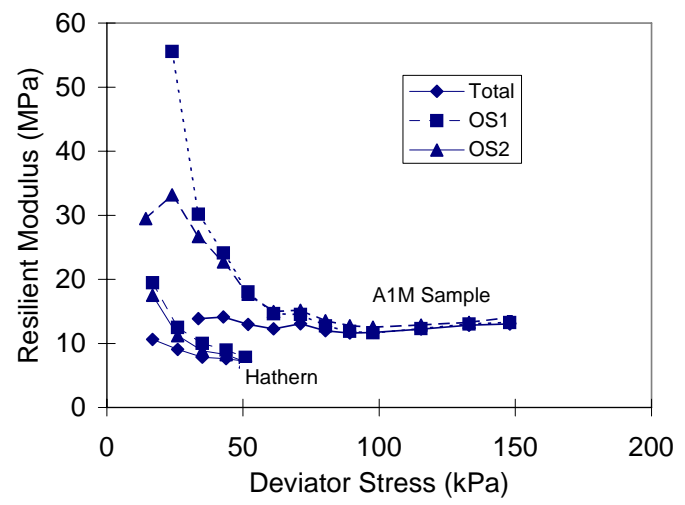

Figure 3. Relationship between Resilient

Modulus and Deviator Stress for Two Undis-

turbed Samples. Results are plotted for the Two

On-Sample Measuring Loops (OS1 and 2) and

Total Sample Strain. 


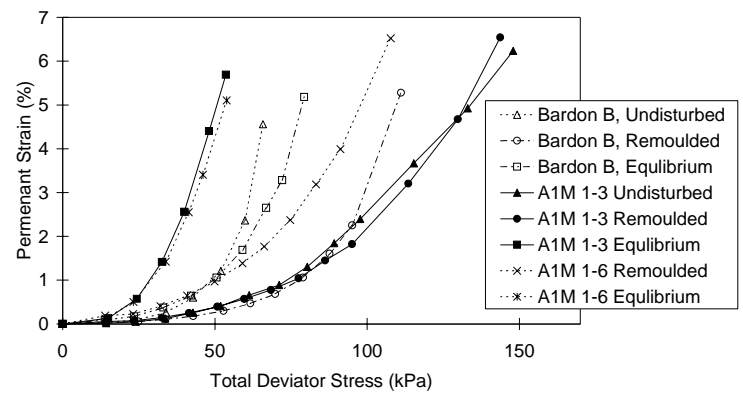

Figure 4. Relationship between Permanent Strain and Deviator Stress for Samples from Bardon and the A1M Prepared in Three Different States (Average of On-Sample Strain Loop Readings). Note: 'remolded' refers to samples at in-situ water content and 'equilibrium' refers to samples remolded at the predicted equilibrium water content. 


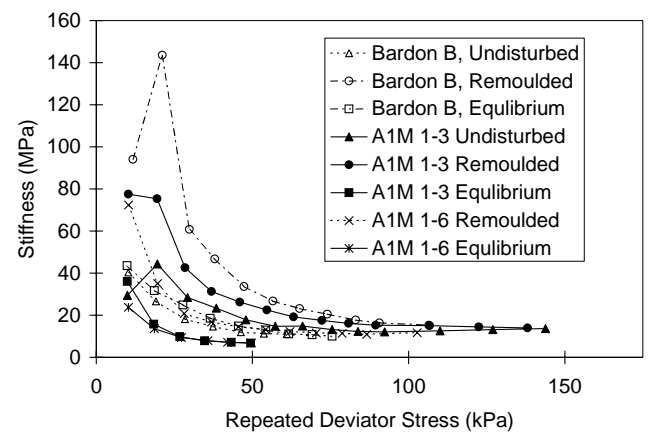

Figure 5. Relationship between Resilient

Modulus and Deviator Stress for Samples from

Bardon and the A1M Prepared in Three Different

States (Average of On-Sample Strain Loop Read-

ings). Note: 'remolded' refers to samples at in-

situ water content and ‘equilibrium’ refers to

samples remolded at the predicted equilibrium

water content. 


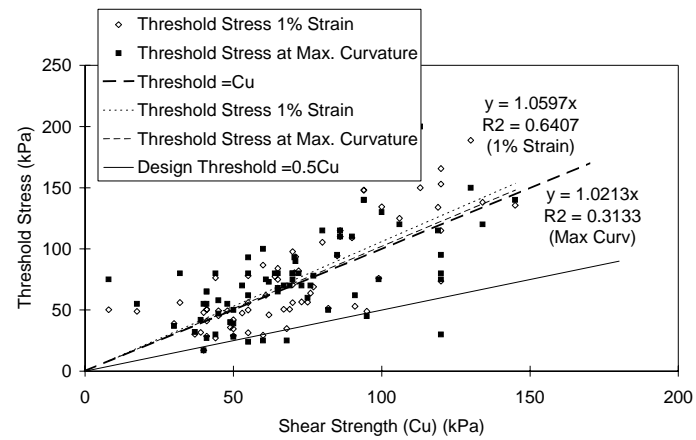

Figure 6. Relationship between Threshold Stress and Undrained Shear Strength.

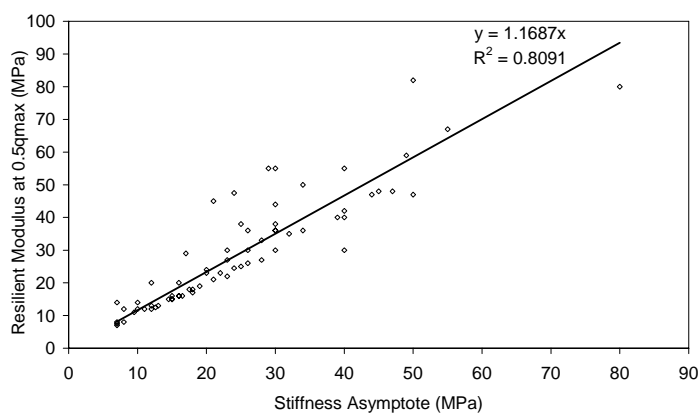

Figure 7. Relationship between Resilient Modulus at Threshold Stress and 'Stiffness Asymptote'. 
